\title{
AGE DIFFERENCES IN BEHAVIORAL INTENTION TO USE INTERNET MARKETING: A COMPARATIVE STUDY BETWEEN MALAYSIAN AND TAIWANESE
}

\author{
Salmi Mohd Isa* \\ Universiti Sains Malaysia \\ Khang-Yeu Wong \\ Universiti Sains Malaysia
}

\begin{abstract}
This study demonstrates the adaptation of Unified Theory of Acceptance and Use of Technology (UTAUT) to examine the moderating roles of age differences that influence the intention to use internet marketing in Malaysia and Taiwan. The result obtained from Malaysia and Taiwan shows a very different situation for both countries. Based on the result, Malaysian was still at the early stage of the era of internet marketing and still very dependent on the performance expectancy, effort expectancy, social influence, facilitating condition and price value in order to use internet marketing. Whereas for the Taiwanese, the internet marketing trend is already mature. It has become a norm for Taiwanese to use internet marketing and internet marketing has become the core marketing channels. In this study, age does not moderate the relationship of the determinants towards the intention to use internet marketing for both Malaysian and Taiwanese. The research provides an in-depth understanding of Malaysia and Taiwan consumer's intention to use internet marketing. The research findings can be used by internet service provider or policy maker to formulate strategies to position the use of internet marketing.
\end{abstract}

Keywords: Internet Marketing; Age; Intention to Use; Unified Theory of Acceptance.

\section{INTRODUCTION}

Internet marketing is the advertising and marketing efforts that use the internet and email to drive direct sales via electronic commerce. Since the creation of internet, many possibilities that the internet can provide had been explored and internet as a marketing tool is one of the greatest exploration. Internet marketing has become the most exciting and fastest growing branch of marketing nowadays. In this revolutionary era, one of the greatest and the most significant marketing tool for the global marketplace is still internet marketing (Samiee, 1998). Malaysia and Taiwan are actively developing the internet facility. Internet marketing activities in these two countries have been complemented by these developments. Though the

2 Corresponding author: Dr. Salmi Mohd Isa. Graduate School of Business, Universiti Sains Malaysia, 11800 USM, Penang, Malaysia. Email: salmi.mohd.isa@usm.my 
developments of internet and internet marketing services are occurring in every country, the consumer response towards internet marketing over conventional marketing medium might not be the same across countries due to the different perceptions and also the difference in culture. Therefore to better understand the global online consumer behavior, a cross-cultural study is required as envisaged by Jarvenpaa Tractinsky \& Saarinen (1999). There are very limited comparative studies on consumer behavior towards internet marketing (Al-Qeisi, 2009). Most of the studies focused on the internet use instead of internet marketing. Therefore this study is conducted to investigate the age factor influencing intention to use internet marketing by Malaysians and Taiwainese.

\section{LITERATURE REVIEW}

\subsection{Unified theory of acceptance and use of technology (UTAUT)}

UTAUT has four dimensions, (1) performance expectancy; (2) effort expectancy; (3) social influence; and (4) facilitating conditions which were identified as direct determinants of users' behavioral intention and subsequently technology usage (Venkatesh, Morris, Davis and Davis, 2003). Recently, UTAUT2 was introduced and the authors added three more dimensions which are (1) hedonic motivation; (2) price value; and (3) habit, to the original UTAUT model (Ventakesh, Thong and $\mathrm{Xu}, 2012$ ). According to them, the UTAUT2 model was tailored to a consumer use context. All seven dimensions from the UTAUT2 were used to examine behavioral intention, which is defined in this study as users' intention rather than actual use of internet marketing. Moreover, the age was hypothesized to moderate the effects of these constructs on behavioral intention and technology use.

\subsection{Performance expectancy and age}

In the context of this study, performance expectancy refers to the belief that users will gain benefits such as increased productivity, efficiency, and time saving as a result of the availability and customization of information by using internet marketing (Srinivasan, Anderson and Ponnavolu, 2002). In fact, excessive amount of information and service required are eliminated by customization and the interest of users in browsing a site is raised (Ansari and Mela, 2003). It is believed that performance expectancy will influence behavioral change towards greater intention to use internet marketing. In this relationship between the performance expectancy and behavioral intention, age however played a moderating role. Age differences have been shown to exist in technology adoption contexts. Research on job-related suggests that younger people may place more importance on extrinsic rewards (Hall and Mansfield, 1975).

\subsection{Effort expectancy and age}

Effort expectancy refers to the degree of ease associated with the use of a particular system (Venkatesh et al., 2003). Adapted from the study of Venkatesh et al. (2003), end-users' direct use experience with the system in terms of changing their perceptions and adoption intentions can be influenced by longer experience in information systems use (Rahman, Jamaludin and Mahmud, 2011). Therefore Szajna (1996) expects effort expectancy to be significant in the 
early adoption stages of a system, but non-significant in later stages of the system. Besides that, age also moderates the relationship between effort expectancy and behavioral intention. According to Plude and Hoyer (1985), people with older age will have difficulty in processing complex stimuli and allocating attention to information on the job.

\subsection{Social influence and age}

Social influence is defined by Venkatesh et al. (2003) as the degree to which an individual perceives the importance of others' beliefs that he or she should use the new system. In the context of this study, personal connections have been identified to facilitate behavior of users (Kim and Tran, 2013) towards intention to use internet marketing. With the popularity of social media, many new functions are introduced by the social media which include providing platform for consumers to share their personal evaluations of the purchased products which facilitate word-of-mouth communication (Brown, 2012). Affiliation needs increase with age, suggesting that older people are more likely to place increased salience on social influence, with the effect declining with experience.

\subsection{Facilitating condition and age}

Facilitating condition is defined as the degree to which an individual believes that an organizational and technical infrastructure exists to support the system use (Venkatesh et al., 2003). In the context of this study, the technology stated in the behavioral intention in using technology is internet marketing. The facilitating condition of the internet marketing that should be present includes excellent user interface, and this includes ease of access, navigation and searching (Fang and Salvendy, 2003) to encourage internet marketing use and with better result if there are proper guidance provided. Besides that, other conditions such as include costs and other resources associated with such use, and the prior knowledge that users must have before use internet marketing could be used by them. Age have a moderating effect on the relationship between facilitating conditions and the intention to use technology. Older people will emphasize more on facilitating conditions compare to the young people.

\subsection{Hedonic Motivation and age}

Hedonic motivation is defined as the fun or pleasure derived from using a technology. Hedonic motivation was shown to play an important role in determining technology acceptance and use (Brown and Venkatesh, 2005). In the research, it has been discovered that such hedonic motivation, which is conceptualized as perceived enjoyment, influence technology acceptance and use directly (Thong, Hong and Tam, 2006). In the consumer context, hedonic motivation is found that it is an important determinant for technology acceptance and use (Brown and Venkatesh, 2005). Age is related to the intention to use technology. Young people tend to exhibit a higher tendency to seek novelty and innovativeness during the early stages of using technology (Chau and Hui, 1998). The higher tendency will then increase the relative importance of hedonic motivation in younger people's early technology use decisions, which in the case of this study, the intention to use internet marketing. 


\subsection{Price Value and age}

There is a difference between the organizational use setting and a consumer use setting is that the consumers usually need to bear the monetary cost whereas employees of an organization do not. Therefore there will be a significant impact on consumers' technology use by the cost and pricing structure. The monetary cost or price is usually conceptualized together with the quality of products or services to determine the perceived value of products or services (Zeithaml, 1988) in marketing research. When the benefits of using a technology are perceived to be greater than the monetary cost, the price value is positive and such price value has a positive impact on intention to use a technology. Similar to other predictor, price value was moderated by the age. The differential importance of price value among younger versus older individuals was theorized with the adaption of theories about social roles (Deaux and Lewis, 1984). Younger people are believed to be less price sensitive compared to the old people.

\subsection{Habit and age}

Habit is defined as the extent to which people tend to perform behavior automatically because of learning (Limayem, Hirt, and Cheung, 2007), while Kim. Malhotra and Narasimhan (2005) equate habit with automaticity. Habit was found to have impact on the intention to use technology as the habit of using the technology will cause the consumer to continue using the technology. Or in other way, habit of not using the technology will prevent the person to learn the use of the technology. It has been found that older people tend to rely largely on automatic information processing (Jennings and Jacoby, 1993), with their habits preventing or suppressing new learning (Lustig, Konkel and Jacoby, 2004).

\section{RESEARCH METHODOLOGY}

A self-reporting questionnaire was used as the research instrument. The questionnaires were distributed mainly based on online survey and small portion of the questionnaires were distributed through the traditional method which is the survey forms. There are total 346 questionnaires were distributed in Malaysia and 243 questionnaires were distributed in Taiwan. There targeted population for Taiwanese is mainly in Taipei city and Kaohsiung city, whereas for Malaysian is mainly in Kuala Lumpur and Penang. These cities have almost same standard of living and same level of development in internet facility. In this study, 312 completed responses were collected which have 53.1\% response rate. However, 17 responses were in-completed, as a result, a total of 295 sets of questionnaire were actually valid and used for this analysis which contributed to $50.1 \%$ response rates.

From the data collected, there were male and female which is $55.5 \%$ and $45.5 \%$ respectively in Malaysia whereas $55.6 \%$ and $44.4 \%$ respectively in Taiwan. Besides that, the responses from both Malaysia and Taiwan are skewed towards younger people who are younger than 30 years old. From the data collected, $47.7 \%$ of respondents from Malaysia are people age between 20 and 30, whereas $57.7 \%$ of respondents from Taiwan are people age between 20 and 30 . They were relatively highly educated. In addition, the data shows that $54.3 \%$ of the Malaysian and $69.4 \%$ Taiwanese have experience in using internet marketing. Table 1 shows the demographic profile of respondents. 
Table 1: Demographic profiles of respondents

\begin{tabular}{|c|c|c|c|c|}
\hline & \multicolumn{4}{|c|}{ Nationality } \\
\hline & \multicolumn{2}{|c|}{ Malaysian } & \multicolumn{2}{|c|}{ Taiwanese } \\
\hline & Frequency & $\%$ & Frequency & $\%$ \\
\hline \multicolumn{5}{|l|}{ Gender } \\
\hline Male & 83 & 55.0 & 80 & 55.6 \\
\hline Female & 68 & 45.0 & 64 & 44.4 \\
\hline \multicolumn{5}{|l|}{ Age group } \\
\hline $20-24$ & 19 & 12.6 & 43 & 29.9 \\
\hline $25-29$ & 53 & 35.1 & 40 & 27.8 \\
\hline $30-34$ & 38 & 25.2 & 29 & 20.1 \\
\hline $35-39$ & 23 & 15.2 & 20 & 13.9 \\
\hline $40-44$ & 11 & 7.3 & 8 & 5.6 \\
\hline More than 45 & 7 & 4.6 & 4 & 2.8 \\
\hline \multicolumn{5}{|l|}{ Education level } \\
\hline High school & 18 & 11.9 & 11 & 7.6 \\
\hline Diploma/Certificate & 16 & 10.6 & 11 & 7.6 \\
\hline Degree & 87 & 57.6 & 94 & 65.3 \\
\hline Master degree & 30 & 19.9 & 28 & 19.4 \\
\hline PHD & 0 & 0.0 & 0 & 0.0 \\
\hline \multicolumn{5}{|l|}{ Owning a web site } \\
\hline Yes & 22 & 14.6 & 21 & 14.6 \\
\hline No & 129 & 85.4 & 123 & 85.4 \\
\hline \multicolumn{5}{|l|}{ Usage of Facebook } \\
\hline Yes & 151 & 100.0 & 138 & 95.8 \\
\hline No & 0 & 0.0 & 6 & 4.2 \\
\hline \multicolumn{5}{|c|}{ Usage on checking e-mails } \\
\hline Yes & 151 & 100.0 & 141 & 97.9 \\
\hline No & 0 & 0.0 & 3 & 2.1 \\
\hline \multicolumn{5}{|c|}{ Usage on checking for information } \\
\hline Yes & 151 & 100.0 & 140 & 97.2 \\
\hline No & 0 & 0.0 & 4 & 2.8 \\
\hline \multicolumn{5}{|l|}{ Usage on entertainment } \\
\hline Yes & 143 & 94.7 & 135 & 93.8 \\
\hline No & 8 & 5.3 & 9 & 6.3 \\
\hline \multicolumn{5}{|c|}{ Experience in using internet marketing } \\
\hline Yes & 82 & 54.3 & 44 & 69.4 \\
\hline No & 69 & 45.7 & 100 & 30.6 \\
\hline
\end{tabular}




\section{ANALYSIS AND RESULTS}

In order to examined the result of hypotheses tests, the bootstrapping was used and the minimum number of bootstrap samples of 500 were selected, critical values for a one-tailed test was applied where 1.65 (significance level $=5 \%$ ), and 2.33 (significance level $=1 \%$ ) (Hair, Hult, Ringle and Sarstedt, 2013). Refer to Table 2 and Table 3, and also Figures 1 and Figure 2, for the hypotheses testing and bootstrapping results.

Table 2: PLS Results of Direct Effect

\begin{tabular}{ccccc}
\hline \hline Hypothesis & Relationship & Country & t-value & Result \\
\hline \hline $\mathrm{H} 1 \mathrm{a}$ & \multirow{2}{*}{ Performance Expectancy $(\mathrm{PE}) \rightarrow$ Behavioral Intention $(\mathrm{BI})$} & Malaysia & $1.750^{*}$ & Supported \\
$\mathrm{H} 1 \mathrm{~b}$ & & Taiwan & 0.191 & Not Supported \\
\hline $\mathrm{H} 2 \mathrm{a}$ & \multirow{2}{*}{ Effort Expectancy $(\mathrm{EE}) \rightarrow$ Behavioral Intention $(\mathrm{BI})$} & Malaysia & $1.656^{*}$ & Supported \\
$\mathrm{H} 2 \mathrm{~b}$ & & Taiwan & $2.198^{*}$ & Supported \\
\hline $\mathrm{H} 3 \mathrm{a}$ & \multirow{2}{*}{ Social Influence $(\mathrm{SI}) \rightarrow$ Behavioral Intention $(\mathrm{BI})$} & Malaysia & $2.211^{*}$ & Supported \\
$\mathrm{H} 3 \mathrm{~b}$ & & Taiwan & $3.517^{* *}$ & Supported \\
\hline $\mathrm{H} 4 \mathrm{a}$ & \multirow{2}{*}{ Facilitating Condition $(\mathrm{FC}) \rightarrow$ Behavioral Intention $(\mathrm{BI})$} & Malaysia & $2.196^{*}$ & Supported \\
$\mathrm{H} 4 \mathrm{~b}$ & & Taiwan & 0.393 & Not Supported \\
\hline $\mathrm{H} 5 \mathrm{a}$ & \multirow{2}{*}{ Hedonic Motivation $(\mathrm{HM}) \rightarrow$ Behavioral Intention $(\mathrm{BI})$} & Malaysia & 1.393 & Not Supported \\
$\mathrm{H} 5 \mathrm{~b}$ & & Taiwan & $1.802^{*}$ & Supported \\
\hline $\mathrm{H} 6 \mathrm{a}$ & \multirow{2}{*}{ Price Value $(\mathrm{PV}) \rightarrow$ Behavioral Intention $(\mathrm{BI})$} & Malaysia & $4.330^{* *}$ & Supported \\
$\mathrm{H} 6 \mathrm{~b}$ & & Taiwan & 1.203 & Not Supported \\
\hline $\mathrm{H} 7 \mathrm{a}$ & \multirow{2}{*}{ Habit $(\mathrm{HA}) \rightarrow$ Behavioral Intention $(\mathrm{BI})$} & Malaysia & 0.148 & Not Supported \\
$\mathrm{H} 7 \mathrm{~b}$ & & Taiwan & $5.856^{* *}$ & Supported \\
\hline \hline
\end{tabular}

Notes: $* * \mathrm{p}<.05 . * * * \mathrm{p}<.01$.

Figure 1: Results of Bootstrapping (Malaysia)

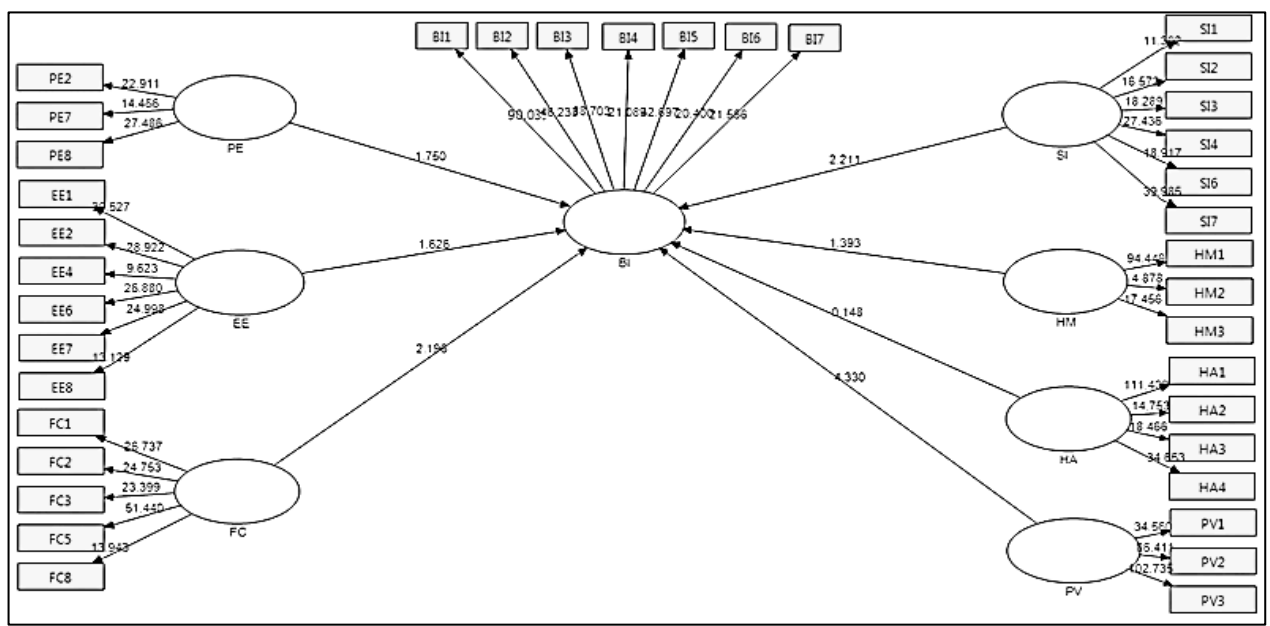

Notes: Performance Expectancy (PE), Effort Expectancy (EE), Social Influence (SI), Facilitating Condition (FC), Hedonic Motivation (HM), Price Value (PV), Habit (HA), Behavioural Intention of using Internet Marketing (BI). 
The result indicated that the first hypothesis has a different result between Malaysia and Taiwan. In Malaysia H1a was supported but in Taiwan H1b was not supported by the result. The second hypothesis and third hypothesis were supported for both Malaysia and Taiwan. Meanwhile, for the fourth hypothesis, H4a was supported whereas H4b was not supported by the result. For the fifth hypothesis, H5a was not supported but H5b was supported by the result. For the sixth hypothesis, H6a was supported whereas H6b was not supported by the result. Next, the seventh hypothesis, H7a was not supported whereas H7b was supported by the result. In the nutshell, hypothesis two and hypothesis three which investigate the relationship between effort expectancy and social influence towards behavioral intention had the same result between Malaysia and Taiwan. Meanwhile, other hypotheses had shown different results between Malaysia and Taiwan.

Figure 2: Results of Bootstrapping (Taiwan)

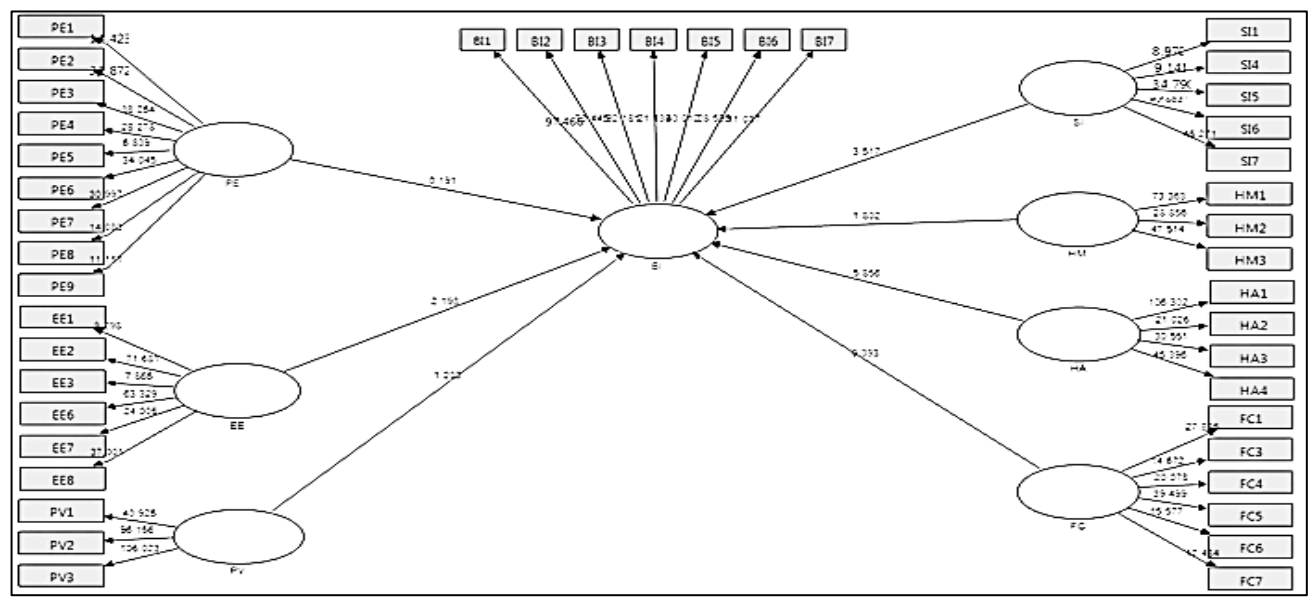

Notes: Performance Expectancy (PE), Effort Expectancy (EE), Social Influence (SI), Facilitating Condition (FC), Hedonic Motivation (HM), Price Value (PV), Habit (HA), Behavioural Intention of using Internet Marketing (BI).

Meanwhile, the moderator in this study is the age difference, the respondents were categorized into two age group which is from age 20 to age 29 and from age 30 onwards. The age category was decided based on the consideration of generation $\mathrm{Y}$ and $\mathrm{X}$. There is no significant effect by the age moderator towards the relationship between the independent variables and the dependent variable which is the intention to use internet marketing in both Malaysia and Taiwan. Table 3 shows the summary hypothesis of the age moderating effect, with all hypotheses regarding age moderator rejected. 
Table 3: PLS Results of Moderating Effect.

\begin{tabular}{ccccc}
\hline \hline Hypothesis & Relationship & Country & t-value & Result \\
\hline \hline $\mathrm{H} 8 \mathrm{a}$ & \multirow{2}{*}{ Performance Expectancy $(\mathrm{PE}) \rightarrow$ Behavioral Intention $(\mathrm{BI})$} & Malaysia & 0.147 & Not Supported \\
$\mathrm{H} 8 \mathrm{~b}$ & & Taiwan & 1.091 & Not Supported \\
\hline $\mathrm{H} 8 \mathrm{c}$ & \multirow{2}{*}{ Effort Expectancy $(\mathrm{EE}) \rightarrow$ Behavioral Intention $(\mathrm{BI})$} & Malaysia & 0.181 & Not Supported \\
$\mathrm{H} 8 \mathrm{~d}$ & & Taiwan & 1.347 & Not Supported \\
\hline $\mathrm{H} 8 \mathrm{e}$ & \multirow{2}{*}{ Social Influence $(\mathrm{SI}) \rightarrow$ Behavioral Intention $(\mathrm{BI})$} & Malaysia & 0.191 & Not Supported \\
$\mathrm{H} 8 \mathrm{f}$ & & Taiwan & 0.053 & Not Supported \\
\hline $\mathrm{H} 8 \mathrm{~g}$ & \multirow{2}{*}{ Facilitating Condition $(\mathrm{FC}) \rightarrow$ Behavioral Intention $(\mathrm{BI})$} & Malaysia & 0.227 & Not Supported \\
$\mathrm{H} 8 \mathrm{~h}$ & & Taiwan & 0.259 & Not Supported \\
\hline $\mathrm{H} 8 \mathrm{i}$ & \multirow{2}{*}{ Hedonic Motivation $(\mathrm{HM}) \rightarrow$ Behavioral Intention $(\mathrm{BI})$} & Malaysia & 0.359 & Not Supported \\
$\mathrm{H} 8 \mathrm{j}$ & & Taiwan & 0.791 & Not Supported \\
\hline $\mathrm{H} 8 \mathrm{k}$ & \multirow{2}{*}{ Price Value $(\mathrm{PV}) \rightarrow$ Behavioral Intention $(\mathrm{BI})$} & Malaysia & 0.087 & Not Supported \\
$\mathrm{H} 8 \mathrm{i}$ & & Taiwan & 1.405 & Not Supported \\
\hline $\mathrm{H} 8 \mathrm{~m}$ & \multirow{2}{*}{ Habit $(\mathrm{HA}) \rightarrow$ Behavioral Intention $(\mathrm{BI})$} & Malaysia & 0.001 & Not Supported \\
$\mathrm{H} 8 \mathrm{n}$ & & Taiwan & 0.573 & Not Supported \\
\hline \hline
\end{tabular}

Notes: $* * p<.05 . * * *<.01$.

\section{DISCUSSION AND CONCLUSION}

Performance expectancy was found to have positive relationship with behavioral intention of using internet marketing for Malaysian, but this relationship was not significant for the Taiwanese. Taiwanese are familiar to the used of internet marketing. Thus they no longer expected the better performance and efficiency brought by the internet marketing. On the other hand, internet marketing is considered new to the Malaysian. Thus, performance improvement and better efficiency of the internet marketing will be appreciated by the Malaysian. Similarly, Tan, Chong and Lin (2013) also found that the performance expectancy has a positive relationship with intention to use internet marketing for Malaysian. Besides that, the result also shows that Malaysians is aware about the importance of internet marketing. Therefore, they are ready to accept of more internet marketing tools in the future.

Contradict to Tan et al. (2013), effort expectancy shows a positive relationship with intention to use internet marketing in both Malaysian and Taiwanese. This study found that Malaysian is still in the early stages of internet marketing use. Thus, they perceive that more efforts are required. Based on the result it shows the importance of having user friendly and easy to use internet marketing tools, in order to capture the interest of the consumer in both Malaysia and Taiwan.

Next, social influence is found to have positive relationship with the intention to use internet marketing for both Malaysian and Taiwanese. The result is also contradicted with Tan et al. (2013). This is because in the previous study, they targeted respondent age from 19 to 35 which are the generation Y. However in this study, the targeted respondents were from generation Y and $\mathrm{X}$ ages. The findings indicate that social influence may affect the use of internet marketing for both Malaysian and Taiwanese. Facilitating condition shows a positive relationship for Malaysian. Whereby there is no significant relationship between facilitating condition and intention to use internet marketing for the Taiwanese. Malaysian is still dependent on the 
facility and reliable infrastructure on the internet connection. If they do not receive the internet accommodation, Malaysian might choose to use the traditional channel of marketing. The hedonic motivation does not affect the intention to use internet marketing in Malaysia. Malaysia is still in the early stage of internet marketing. At the moment, internet marketing tool used by Malaysian are at fundamental level. On the other hand, Taiwanese are not interested towards the advanced features in the internet marketing., Taiwanese are prefer on formal and professional internet marketing tools. They are not keen towards internet marketing that has complicated features and function.

Meanwhile, price value shows a positive relationship towards behavioral intention of using internet marketing for Malaysian. This result indicates that the intention of Malaysian to use internet marketing is very dependent on the price of the internet marketing. Malaysian might prefer to use the traditional marketing channel if the cost of using internet marketing is high. However, price value shows no significant relationship towards the intention to use internet marketing for the Taiwanese. This is because Taiwanese is accepted internet marketing as the core marketing channel and it is becoming the norm of marketing practice.

On the other hand, habit shows a positive relationship towards the intention of using internet marketing for the Taiwanese but not for Malaysian. Taiwan has advance internet facilities for the country. Thus, the use of internet marketing by Taiwanese already becomes habit and trend in their society.

Interestingly, age does not moderate any relationship between determinants in the UTAUT model as discussed above towards the intention to use internet marketing for both Malaysian and Taiwanese. This finding shows that age is not a factor to influence the intention to use internet marketing. Generally, the use of internet marketing is applicable to anyone without considering of the age differences. Old or young people might have a tendency to use the internet marketing.

In conclusion, this study has demonstrated that age do not moderate the relationship between performance expectancy, effort expectancy, social influence, facilitating condition, hedonic motivation, price value and habit towards the intention to use internet marketing. Despite the limitation of the study, the current findings will be useful for the organization or policy maker to improve the use of internet marketing. Future research can contribute substantially to more understanding of the intention to use internet marketing by investigating the effect of culture towards the intention to use internet marketing. Comparison can be made to discover the effect of different cultures. 


\section{REFERENCES}

Al-Qeisi, K. I. (2009). Analyzing the use of UTAUT model in explaining an online behaviour: Internet banking adoption (Doctoral dissertation, Brunel University Brunel Business School).

Ansari, A., \& Mela, C. F. (2003). E-customization. Journal of Marketing Research, 40(2), 131-145.

Brown, E. (2012). Working the crowd: Social media marketing for business. United Kingdom: British Company Society, British Informatics Society.

Brown, S. A., \& Venkatesh, V. (2005). A Model of Adoption of Technology in the Household: A Baseline Model Test and Extension Incorporating Household Life Cycle. Management Information Systems Quarterly, 29(3), 399-426.

Chau, P. Y., \& Hui, K. L. (1998). Identifying early adopters of new IT products: A case of Windows 95. Information \& Management, 33(5), 225-230.

Deaux, K., \& Lewis, L. L. (1984). Structure of gender stereotypes: Interrelationships among components and gender label. Journal of personality and Social Psychology, 46(5), 9911004 .

Fang, X., \& Salvendy, G. (2003). Customer-centered rules for design of e-commerce Web sites. Communications of the ACM, 46(12), 332-336.

Hair, J. F., Hult, G. T. M., Ringle, C., \& Sarstedt, M. (2013). A primer on partial least squares structural equation modeling (PLS-SEM). Thousand Oaks: Sage Publications.

Hall, D. T., \& Mansfield, R. (1975). Relationships of age and seniority with career variables of engineers and scientists. Journal of Applied Psychology, 60(2), 201-210.

Jarvenpaa, S. L., Tractinsky, N., \& Saarinen, L. (1999). Consumer trust in an internet store: a cross-cultural validation. Journal of Computer-Mediated Communication, 5(2),

Jennings, J. M., \& Jacoby, L. L. (1993). Automatic versus intentional uses of memory: aging, attention, and control. Psychology and aging, 8(2), 283-293

Kim, S. S., Malhotra, N. K., \& Narasimhan, S. (2005). Research note-two competing perspectives on automatic use: A theoretical and empirical comparison. Information Systems Research, 16(4), 418-432.

Kim, Y. S., \& Tran, V. L. (2013). Assessing the ripple effects of online opinion leaders with trust and distrust metrics. Expert Systems with Applications, 40(9), 3500-3511. 
Limayem, M., Hirt, S. G., \& Cheung, C. M. (2007). How habit limits the predictive power of intention: The case of information systems continuance. MIS Quarterly, 31(4), 705-737.

Lustig, C., Konkel, A., \& Jacoby, L. L. (2004). Which route to recovery? Controlled retrieval and accessibility bias in retroactive interference. Psychological Science, 15(11), 729735.

Plude, D. J., \& Hoyer, W. J. (1985). Attention and performance: Identifying and localizing age deficits. In N. Charness (Eds.), Aging and human performance (pp. 47-99). University of Michigan: Wiley.

Rahman, A. L. A., Jamaludin, A., \& Mahmud, Z. (2011). Intention to use digital library based on modified UTAUT model: Perspectives of Malaysian postgraduate students. World academy of science, Engineering and technology, 54, 116-122.

Samiee, S. (1998). The internet and international marketing: is there a fit? Journal of Interactive Marketing, 12(4), 5-21.

Srinivasan, S. S., Anderson, R., \& Ponnavolu, K. (2002). Customer loyalty in e-commerce: an exploration of its antecedents and consequences. Journal of retailing, 78(1), 41-50.

Szajna, B. (1996). Empirical evaluation of the revised technology acceptance model. Management science, 42(1), 85-92.

Tan, K. S., Chong, S. C., \& Lin, B. (2013). Intention to use internet marketing: A comparative study between Malaysians and South Koreans. Kybernetes, 42(6), 888-905.

Thong J. Y. L., Hong, S. J., and Tam, K. Y. (2006). "The Effects of Post-Adoption Beliefs on the Expectation-Confirmation Model for Information Technology Continuance," International Journal of Human-Computer Studies (64:9), pp. 799-810.

Venkatesh, V., Morris, M. G., Davis, G. B., \& Davis, F. D. (2003). User acceptance of information technology: Toward a unified view. Management Information Systems Quarterly, 27(3), 425-478.

Venkatesh, V., Thong, J. Y., \& Xu, X. (2012). Consumer acceptance and use of information technology: extending the unified theory of acceptance and use of technology. Management Information Systems Quarterly, 36(1), 157-178.

Zeithaml, V. A. (1988). Consumer perceptions of price, quality, and value: a means-end model and synthesis of evidence. The Journal of Marketing, 52(3), 2-22. 